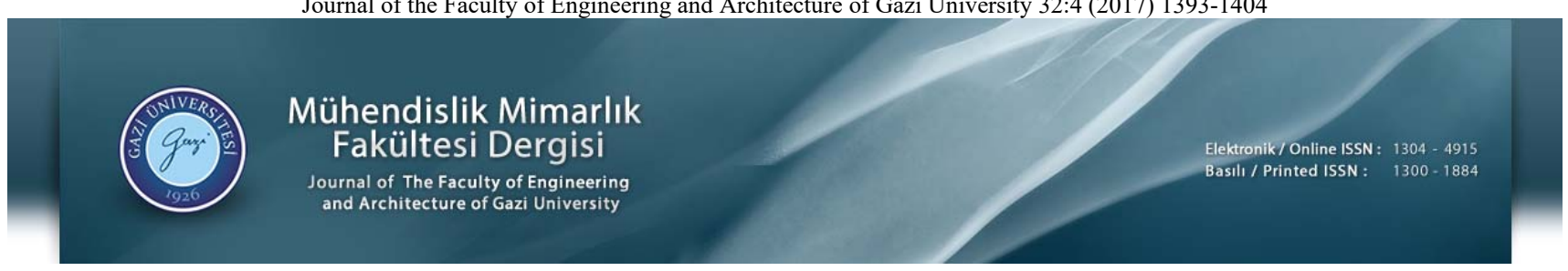

\title{
Su boru hatlarında sızıntı konum tespiti için genişletilmiş kalman filtresi tabanlı IMU sensör füzyonu uygulaması
}

\author{
Abdullah Erhan Akkaya* (D), Muhammed Fatih Talu \\ İnönü Üniversitesi, Mühendislik Fakültesi, Bilgisayar Mühendisliği Bölümü, 44280, Battalgazi, Malatya, Türkiye
}

\section{Ö N E Ç I K A N L A R}

- Su boru hatlarında sızıntı konumlarını ses ve ımu sensör verileri kullanarak tespit eden bir robot tasarlamak

- Genişletilmiş kalman filtresi kullanarak sensör füzyonu yapılması

Makale Bilgileri

Geliș: 09.03.2017

Kabul: 13.05.2017

DOI:

10.17341/gazimmfd.369872

Anahtar Kelimeler:

Sizıntı tespiti, sensör füzyonu,

Genişletilmiş Kalman

Filtresi,

kuaterniyon,

su boru hatları

\section{ÖZET}

Su dağıtım șebekelerinde, borulardaki çatlaklar ve arızalardan dolayı ciddi miktarda su kaybı yașanmaktadır. $\mathrm{Bu}$ arızaların kısa zamanda tespit edilerek onarılması, su ve buna bağlı oluşan gelir kaybının önlenmesi için oldukça önemlidir. Dağıtım șebekelerinde yüksek maliyete sahip genel onarım işlemleri yerine, arızanın kesin konumunun bulunup sadece o bölgede çalışma yapılması onarım maliyetlerini azaltacaktır. Her ne kadar yüzeysel boru dinleme cihazları bu ihtiyaca bir çözüm olarak görünse de, dıș ortam seslerinden etkilenmesi bu yöntemin verimliliğini düşürdüğünden tercih edilmemesine neden olmaktadır. Ticari olarak piyasada mevcut olan modern GPS temelli sistemler, büyük çaplı su borularında çalışabilir ( $\geq 6$ inch) ve yüksek maliyetlere sahiptir. Bu çalışmada daha küçük çaplı borularda ve GPS sistemine ihtiyaç duymadan çalışabilecek bir sızıntı tespit robotu prototipinin ön çalışması sunulmuștur. Bu ön çalıșmada, boru içerisinde suyun itme kuvvetiyle hareket edecek robotun tasarımı, üretimi, konum ve sızıntı tahmin yazılımları gerçekleștirilmiștir. Konum tahmini, 9-dof IMU sensör (3D-ivme, 3D-jiroskop ve 3d-manyetometre) verilerinin Genişletilmiş Kalman Filtresi içerisinde kullanımıyla yapılmaktadır. Sızıntı tahmini, anlık kaydedilen ses verisindeki tepe noktalara karşıllk gelen konumun tespitini içermektedir. Yapılan deneysel çalışmalarda, toplam $118 \mathrm{~m}$ gezintide sonucunda sızıntı konumu tahmin hatasının yaklaşık $0,25 \mathrm{~m}$ olduğu görülmüștür.

\section{Extended kalman filter based IMU sensor fusion application for leakage position detection in water pipelines}

\section{H I G H L I G H T S}

- Designing a robot that detects leakage positions in water pipelines using sound and IMU sensor data

- Sensor fusion using Extended Kalman Filter

Article Info

Received: 09.03.2017

Accepted: 13.05 .2017

DOI:

10.17341/gazimmfd.369872

Keywords:

Leakage detection, sensor fusion,

extended kalman filter, quaternion,

water pipelines

\begin{abstract}
In water distribution networks, there is a serious loss of water due to cracks and faults in pipes. It is very important to detect these failures and fix them in a short period of time to prevent the loss of water and related income. Instead of general repair operations with high costs in distribution networks, finding the exact location of the fault and only working in that area will reduce the repair costs. Although superficial pipe listening devices seem to be the solution to this need, it is not preferred because of affected by the ambient sounds that reducing the efficiency of this method. GPS-based leak detection systems, which are commercially available on the market, can operate on large-scale water pipelines ( $\geq 6$ inch) and have high costs. In this study, we present a preliminary study of a leak detection robot prototype that can operate on smaller diameter pipes and without the need for a GPS system. In this study, a preliminary study of a leak detection robot prototype that can operate on smaller diameter pipes and without the need for a GPS system was presented. In this preliminary study, the design, production, location and leakage prediction software of a robot can move with the pushing force of water in the pipeline has been realized. The position estimation is performed by using the 9-DOF IMU (3D-accelerometer, 3D-gyroscope and 3D-magnetometer) sensor data in the Extended Kalman Filter. The leakage estimation includes the location of the corresponding peak point in the instantaneous recorded sound data. In the performed experimental studies, it was seen that the leakage location estimation error in the total $118 \mathrm{~m}$ navigation result is about $0.25 \mathrm{~m}$.
\end{abstract}




\section{GİRIŞ (INTRODUCTION)}

Su, dünya üzerindeki bütün canlllar için hayati önem arz etmektedir. Dolayısıyla, su kaynaklarının azalması canlı devamlılığını tehdit edecek en büyük tehlikelerden biridir. Nüfus artış1, teknoloji ve sanayi alandaki gelişmeler günden güne içilebilir kaynakları kirletmektedir [1]. Gerek bahsedilen gelişmelere uyum göstererek büyüyen metropol kentlerde gerekse düşük potansiyel büyümeye sahip büyükşehirlerde [2], artan çevre kirliliğine ek olarak şebeke sistemlerindeki arızalar içilebilir su kaynaklarını hızla tüketmektedir. İçme ve kullanım suyu, arıtma tesislerinden tüketicilere ulaştırılana kadar dağıtım sistemindeki kayıplardan ve tüketici sıhhi tesisatındaki problemlerden dolayı, önemli miktarda su kaybı yaşanmaktadır. Dağıtım sistemindeki kayıplar sızıntı temelli olup borularda korozyon, aşırı şebeke basıncı, malzeme üretimindeki kusurlar ve kurulum hatalarından kaynaklanan gerçek kayıplardır. Tüketici tesisatındaki kayıplar ise şebeke sızıntılarının yanı sıra kaçak su kullanımı, sayacın hatalı okunması, hileli sayaç kullanımı gibi gelire dönüşemeyen görünür kayıplardır [3]. Gerçek kayıplar ve görünür kayıpların toplamı Uluslararası Su Birliği (IWA) tarafından "gelir getirmeyen kayıplar" olarak adlandırılmaktadır [4].

Dünya Bankası raporunda tahminlere göre dünya genelinde her y1l ortalama 14,6 milyar dolar değerinde gelir getirmeyen su kaybı yaşanmaktadır [5]. Dünya Bankası'nın hazırladığı bir diğer raporda ise mevcut su politikaları kontrol altına alınmadığ1 takdirde 2025 yılında dünya nüfusunun üçte ikisinin susuz kalacağı öngörülmektedir [6]. Bu bağlamda sızıntı konumunun erken dönemde tespiti ve hatalı boru hattının onarılması önemli miktarda su ve milli gelir kaybının önüne geçecektir. Su borularının genel bakım işlemleri yüksek maliyete sahip olmakla birlikte sızıntı yerinin tam keşfi, kazı çalışmaları ve arızalı boruların yenilenmesi onarım maliyetlerini ciddi oranda artırmaktadır [7]. Kapsamlı boru bakımı: borulardaki su kaybı oranlarının tespiti, su kaybının olduğu borularda çatlakların konum tespiti, çatlak bölgelerin onarılması ve şebeke basıncının ayarlanması olmak üzere dört adımda gerçekleştirilmektedir. Birinci adımda su kaybı oranı tespit edilirken, tüketilen güncel suya karşı1ık faturalandırılmış su kullanım miktarı eşleştirilerek kayıp hakkında tahminler yapılır. İkinci adımda, su borusundan elde edilen basınç, ses ve sıcaklık gibi verilerin analizi sonucu çatlak konumu tespit edilir. Üçüncü adımda çatlakların olduğu sızıntı yapan boru bölgesi onarılır veya yenisiyle değiştirilir. Dördüncü adımda ise şebeke basıncı ayarlanarak boruların yüksek basınç nedeniyle deforme olması engellenir [8]. Bu çalışmada su borusu içerisinde hareket ederek boru çatlağından gelen sesi işleyip konumunu yüksek doğrulukla bulabilen sızıntı tespit robotunun ön çalışması yapılmıştır. Geliştirilen sistem, sizıntı konumunu sadece atalet sensörlerini kullanarak etkin bir şekilde bulmakta ve böylece sensör maliyeti azaltılmaktadır. Yapılan çalışma şu şekilde organize edilmiştir: ikinci bölümde literatürde sızıntı tespiti ile ilgili yapılan çalışmalar incelenerek sızıntı tespit yöntemleri başlığ1 altında sunulmuştur. Üçüncü bölümde sızıntı tespitinde kullanılan robotlar anlatılmıştır. Dördüncü bölümde sensör füzyonunda kullanılan Genişletilmiş Kalman Filtre modeli ve kuaterniyon cebrine yer verilmiştir. Beşinci bölümde yapılan çalışma hakkında bilgiler ve konum hatalarına, altıncı ve son bölümde ise sonuç ve önerilere yer verilmiştir.

\section{SIZINTI TESPIT YÖNTEMLERİ (LEAKAGE DETECTION METHODS)}

Şebeke borularında sızıntı olması durumunda, su basıncının değişmesi, olağanın dişında farklı bir ses oluşması, toprak ıslaklığından dolayı ısının farklılaşması ve su akış vektörünün değişmesi beklenir. Su borularındaki sızıntının tespiti için manuel ve otonom sistemler bulunmaktadır. Manuel sistemlerde, uzman bir kişi yer altındaki boru hattını yer üzerinden dinleyerek çatlak bölgesinden çıkan sesi yakalamaya çalışmaktadır. $\mathrm{Bu}$ ses ve sese bağlı oluşan frekans, kullanılan borunun cinsine ve yer altındaki derinliğe göre değişmektedir. Şekil 1'de manuel yer üstü dinleme uygulaması gösterilmektedir [9]. Manuel sistemler ortam gürültüsünden ciddi şekilde etkilendiği için hata eğilimi yüksek sistemlerdir. $\mathrm{Bu}$ sistemlerde diş ortamdan gelen sesler, borudan gelen zayıf çatlak sesinin duyulmasını engelleyeceğinden dinleme işleminin geceleri sesin az olduğu saatlerde yapılması tercih edilmektedir. Sistem maliyeti düşük olan manuel sistemlerde sızıntı konumu tam olarak tespit edilemediğinden, bu tür sistemler yaygın olarak kullanılmamaktadır.

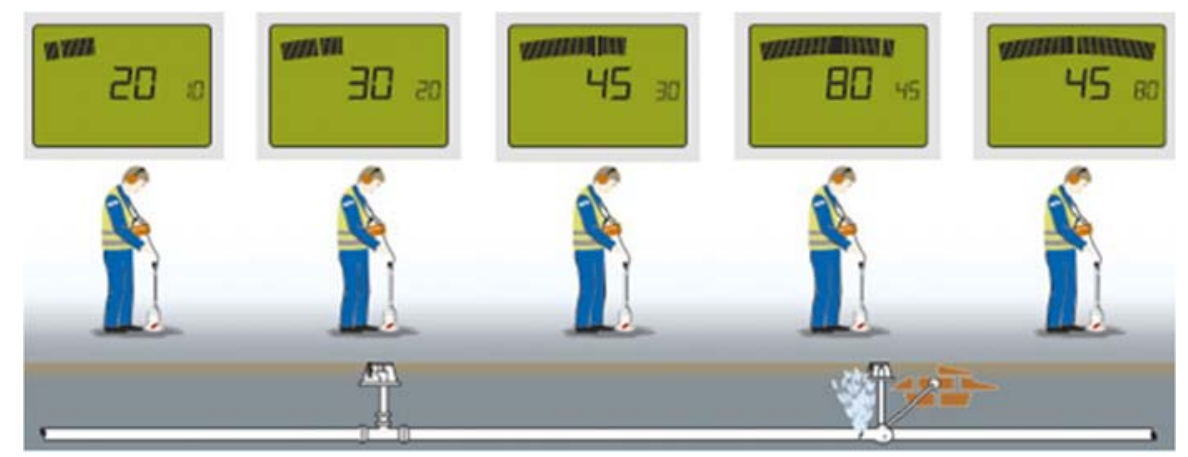

Şekil 1. Sewerin Aquaphon-200 sızıntı tespit sistemi [9] (Sewerin Aquaphon-200 leakage detection system) 
Sızıntı tespitinde kullanılan diğer bir sistem olan otonom sistemlerde, boru içerisinde hareket eden robotlar veya doğrudan su sorusuna temas eden özel cihazlar kullanılmaktadır. Kullanılan robot veya özel cihazlarla şebeke hattından elde edilen ses (Lay-Ekuakille vd. [10]), basınç (Ben-Mansour vd. [11]), sıcaklık (Begovich vd. [12]) veya elektro manyetik dalga (Goh vd. [13]) verileri analiz edilmektedir. Şekil 2'de otonom sistemlerde kullanılan hassas bir dinleme cihazı uygulaması gösterilmektedir. Bu cihaz su borusu üzerine doğrudan temas ettirilerek akustik sinyal elde edilmekte ve daha sonra sinyalin frekans alanında spektrum analizi yapılmaktadır. Sizıntının dinleme yerine uzak olması ve uzun borularda konum doğruluğunun düşmesi yöntemin dezavantajlarındandır.

Frekans alanında akustik sinyal analizi yaygın olarak kullanılmaktadır. $\mathrm{Bu}$ çalışmalarda ses sinyali FFT yöntemiyle frekans ortamına taşındıktan sonra normal ses akışını bozan harmonikler tespit edilmektedir [15]. FFT dönüşümü sonrası zaman bilgisinin kaybolması, hesaplanan çatlak konumunun doğruluğunu azalttığından, bu alandaki araştırmacilar zaman-frekans bilgisinin beraber işlenebileceği yöntemlere yönelmişlerdir [16]. Dalgacık dönüşümü (wavelet) zaman-frekans bilgisinin birlikte işlenmesine imkân verdiğinden akustik veri işlemesinde kullanılmıştır (Ridao vd. [17]). Ridao vd., çalışmalarında wavelet kullanarak sinyalin farklı ölçeklerde dönüşümlerini elde etmiş ve sinyalin kurtosis grafiğini oluşturmuştur. Kurtosis grafiği farklı ölçeklerde frekans değişimlerini ifade etmektedir ve maksimum değişimin olduğu nokta, çatlak sesinin konumuna işaret etmektedir. Nokta tespit edildikten sonra ters dönüşüm yapılarak konum tahmini gerçekleştirilmektedir. Çatlak konumunun zaman domaininde tespiti, frekans alanı çalışmalarının yanında korelasyon tekniğiyle de yapılmaktadır [18]. Bu yöntem yüksek doğruluğa sahiptir. Fakat hesaplama maliyetinin yüksek olması yöntemin dezavantajıdır. Başka bir çalışmada DSP+FPGA kullanımıyla korelasyon tekniğinin hızlanması sağlanmaktadır [19]. Sızıntı konum tespitinde ses verisine ek olarak basınç değişimlerinin (Ben-Mansour vd. [11]), 1s1 değişimlerinin (Begovich [12]), fiber optik kablodaki 1şı̆̆a ait zaman domeni verilerinin (Rajeev vd. [20]), elektromanyetik verilerin analizinin gerçekleştirildiği (Goh vd. [13]), yeraltının radar ile görüntülendiği ve kontör çıkarımı ile sızıntı konum tespitinin yapıldığı (Ayala-
Cabrera vd. [21]) çalışmalar da mevcuttur. Bu çalışmada sadece ses verisi işlenerek konum tespiti yapıldığından diğer verileri kullanan otonom yöntemlere detaylı yer verilmemiştir.

\section{SIZINTI TESPIT ROBOTLARI (LEAKAGE DETECTION ROBOTS)}

$\mathrm{Su}$ ve gaz borularını inceleyerek bakım ve denetim işlemlerini gerçekleştiren birçok robot bulunmaktadır. Bu robotlardan Şekil 3a'da verilen PIG robotu, ultrasonik sensör ile boru içerisinden yankı sesleri toplayarak boru duvar kalınlığını hesaplamaktadır [22]. Kullanılan borunun et kalınlığ 1 bilindiğinden, eldeki verilerle cihaz verisi kıyaslanarak çatlayan bölge ve boru içinde yabanc1 maddelerin biriktiği bölge tespit edilmektedir [23]. Oynar başlıklı kamerası yardımıyla boru iç yüzeyinin birçok açıdan görüntülenmesini sağlayan VersaTrax modüler boru muayene robotu Şekil 3b'de verilmiştir [24]. Şekil 3c'de ise uzaktan kontrol edilebilen ilk doğalgaz denetim robotu olan NREC görülmektedir [25]. Bu robot ön tarafında bulunan kamera yardımıyla boru içerisini görüntülerken, dış kısmında bulunan akustik sensörler ile boru içi sesi dinleyerek sızıntı konumunu tahmin etmektedir. Çoğunlukla yer altında ve erişimin zor olduğu su, gaz, beton [26] ve deniz suyu borularının [27] uzak mesafelerden denetiminin yapılabilmesi kullanıcı için kolaylık sağlamaktadır (Şekil 3d). Fakat bu robotlar sadece geniş çaplı su ve gaz borularında gezinebilmektedir. İleri teknolojik sensörlerle donatılan robotların büyük boyutlarda olması dar çaplı borularda kullanımlarını engellemektedir. Bu çalışmada önerilen robot küçük boyutlarda tasarlanarak bu robotların giremediği dar çaplı borulara girebilecektir.

Pure Technologies tarafından geliştirilen SmartBall bilinen en güncel sızıntı tespit robotudur [28]. Sünger ile kaplanmış alüminyum bir top içerisinde bulunan mini bilgisayar ile boru hattı içerisinde gözlem yapan bu robot ticari olarak piyasada mevcuttur (Şekil 4). Dibe batarak diş yüzeyinde bulunan sünger sayesinde su akışı ile hareket eden bu robot, sensörlerden elde ettiği verileri kablosuz olarak kontrol bilgisayarına aktarmakta ve veriler online olarak değerlendirilmektedir. SmartBall her ne kadar ihtiyacı tam olarak karş1lıyor gibi görünse de dezavantajlara sahiptir. Dış ortama kablosuz olarak veri aktarırken boru içerisinde bulunduğu konumu tespit sürecinde dış ortamda bulunan iki

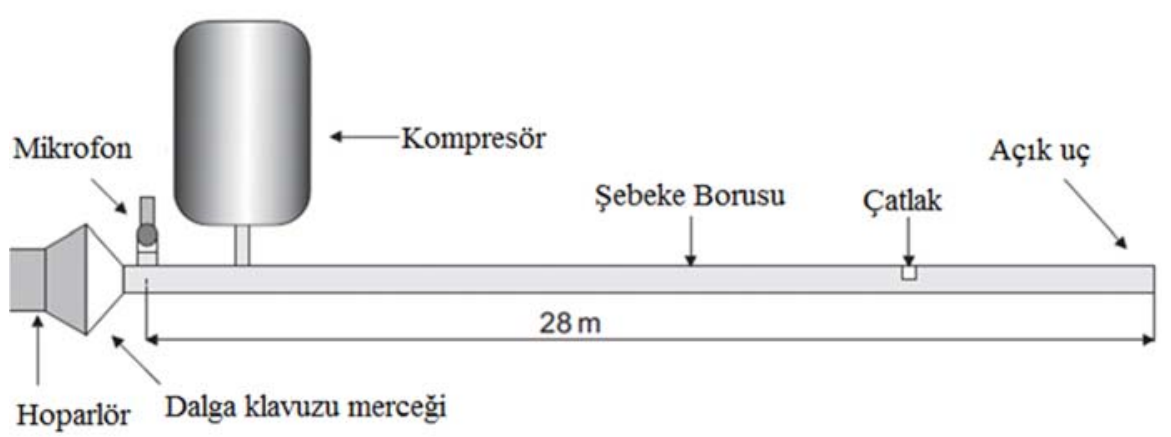

Şekil 2. Spektrum analizi yöntemi ile su borusu dinleme [14] (Pipeline listening via spectrum analysis method) 
adet GPS alıcısını kullanmaktadır. Sonuç olarak sistem bileşen sayısının artmasına ve maliyetin yükselmesine neden olmaktadır. Bir diğer dezavantajı 2,5 inch $(6,35 \mathrm{~cm})$ çapına sahip olan SmartBall en az 6 inch genişliğe sahip borularda gezinebilmektedir. Son olarak konum doğruluğunun yaklaşı 10 feet ( $3 \mathrm{~m}$ ) olması, kilometrelerce uzunluğa sahip boru içerisinde çok iyi bir sonuç olmasına rağmen geliştirmeye açıktır.

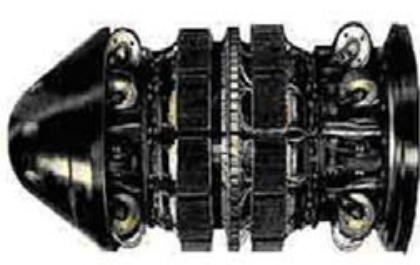

(a)

(c)

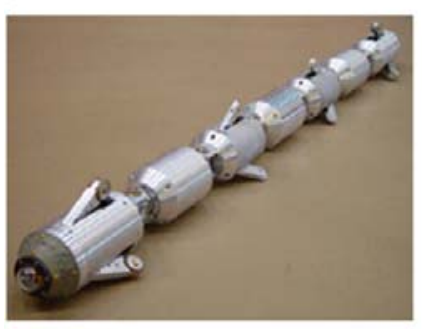

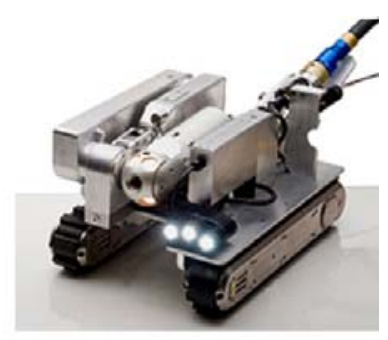

(b)

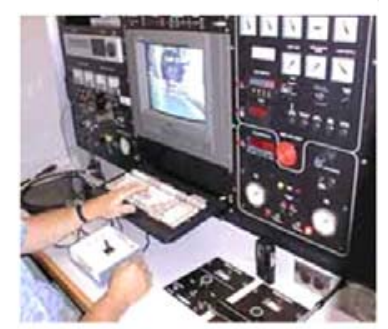

(d)
Şekil 3. a) PIG b) VersaTrax c) NREC d) Uzaktan görüntüleme ve kontrol arac1

(a) PIG b) VersaTrax c) NREC d) Remote monitoring and control equipment)

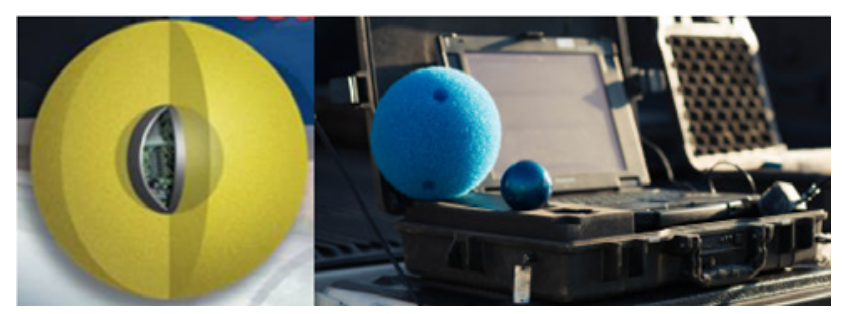

Şekil 4. Pure Technologies tarafından geliştirilen SmartBall (SmartBall developed by pure technologies)

\section{GENİŞLETILMIŞ KALMAN FÍLTRESİ VE SENSÖR FÜZYONU (EXTENDED KALMAN FILTER AND SENSOR FUSION)}

Kesin konumu hesaplamak için kullanılan GPS sensörü dış ortamlarda verimli çalışmasına rağmen, uydu sinyalinin zayıfladığ1 veya tamamen kaybolduğu ortamlarda konumu hatalı olarak bulmaktadır. Bu çalışmada önerilen sızıntı tespit robotunda, mevcut probleme bir çözüm yolu olarak küçük boyutlu, düşük maliyetli ve dış sinyallerden bağımsız çalışabilen Atalet Seyir Sisteminin (Inertial Navigation System - INS) kullanılması önerilmiştir. INS, konum tahmininde gerekli olan manyetik kuvvet, ivme ve açısal hız ölçümlerini Atalet Ölçüm Birimi (Inertial Measurement Unit - IMU) adı verilen mikro elektronik sensör paketi ile gerçekleştirmektedir [29]. Bu sensörler yalıtkan üzerine silisyum (SOI-Silicon-insulator) [30] teknolojisiyle üretilmektedir. Standart bir IMU, manyetik kuvvetölçer (magnetometer), ivmeölçer (accelerometer) ve jiroskop sensörlerinden (gyroscope) oluşmaktadır. Her bir sensörün kendine özgü avantaj ve dezavantajları vardır. İvmeölçer düşük frekansta doğru çalışmasına rağmen yüksek frekanslarda gürültüden etkilenmektedir. Temel olarak, ivmeölçer ve manyetik kuvvetölçer gürültülü yönelim bilgisine sahiptir. Jiroskop anlık açısal değişimi hesaplamaktadır. Başlangıç konumundan itibaren gerçekleşen toplam açısal değişimi hesaplamak için açısal hızlar integral işlemine tabi tutulmaktadır. Jiroskop yüksek frekansta iyi çalışarak ivmeölçerin hatasını düzeltirken düşük frekansta giderek artan sapma hatasına (drift error) neden olmaktadır. Atalet sistemindeki bu hata, konum ve yönelimi hesaplamak için ivmeölçer ve jiroskoptan gelen verilerin zamanda integral işlemine tabi tutulması sonucu oluşmaktadır. İvmeölçer ve manyetik kuvvetölçerde ise sapma hatası olmamaktadır. Birbirinin dezavantajını yok eden sensör verileri birleştirilerek etkin sonuçlar elde etmek mümkündür. Manyetik kuvvetölçer, ivmeölçer ve jiroskop gibi farklı sensörlerden elde edilen verilerin birleştirilerek en az hataya sahip bilgiyi elde etme işlemine sensör füzyonu denilmektedir [31]. Kalman filtresi sensör füzyonunda etkin olarak kullanılmaktadır [32, 35]. Bu bölümde Kalman filtresi hakkında kısa bilgi verildikten sonra bu çalışmada kullanılan kuaterniyon tabanlı Genişletilmiş Kalman Filtre modeli tanitilacaktır.

\subsection{Kalman Filtresi (Kalman Filter)}

Genel olarak Kalman filtresi, dinamik bir sistemi $t-1$ anındaki giriş ve çıkış bilgilerini kullanarak bu sistemin $t$ anındaki durumlarını tahmin edebilen bir filtredir. Kalman Filtresi Eş. 1 ve Eş. 2 ile tanımlamaktadır [36]. Eş. 1'de verilen $x$ durum vektörünü, $u$ kontrol vektörünü, $w$ durum hatasını, $A$ durum geçiş matrisini, $B$ kontrol giriş matrisini temsil etmektedir. Eş. 2'de verilen $z$ ölçüm vektörünü, $H$ durum vektörü parametrelerini ölçüm bölgesine haritalayan dönüşüm matrisini, $v$ ise ölçüm hatasını temsil etmektedir.

$$
\begin{aligned}
& x_{t}=A_{t} x_{t-1}+B_{t} u_{t}+w_{t} \\
& z_{t}=H_{t} x_{t}+v_{t}
\end{aligned}
$$

Kalman filtresi iki adımdan oluşmaktadır. Bu adımlar zaman güncellemesinin yapıldığı tahmin (prediction) ve ölçüm güncellemesinin yapıldığı düzeltme (correction) adımlarıdır. Tahmin adımı, bir sonraki gelecek duruma ait tahminler elde etmek için mevcut durum ve hata kovaryansını hesaplamaktadır. Düzeltme adımı ise sistem geri beslemesi yaparak durum ve kovaryans matrisini güncellemektedir. Şekil 5'de ayrık zamanlı standart Kalman filtresine ait algoritma akış şeması verilmiştir [37]. Tahmin adımındaki $Q_{t}$, gürültülü kontrol giriş değerlerine ilişkin gürültü kovaryans matrisi, $x_{t \mid t-1}$, durumun öncül tahmini, $x_{t-1 \mid t-1}$ önceki 
zaman adımın ait durumun soncul tahmini, $P_{t \mid t-1}$ öncül hata kovaryans matrisi, $P_{t-1 \mid t-1}$ önceki adıma ait soncul hata kovaryans matrisidir. Düzeltme adımındaki $S_{t \mid t-1}, z_{t}$ ölçüm değerinin tahmini kovaryansı, $K_{t}$ soncul hata kovaryansını en aza indirgeyen Kalman kazanc1, $x_{t \mid t}$ durumun soncul tahmini, $M$ değeri $z_{t}$ ölçümünün tahmini dağılım ortalaması, $z_{t}-M$ değeri ölçüm inovasyon değeri, $P_{t \mid t}$ ise soncul hata kovaryans matrisidir.

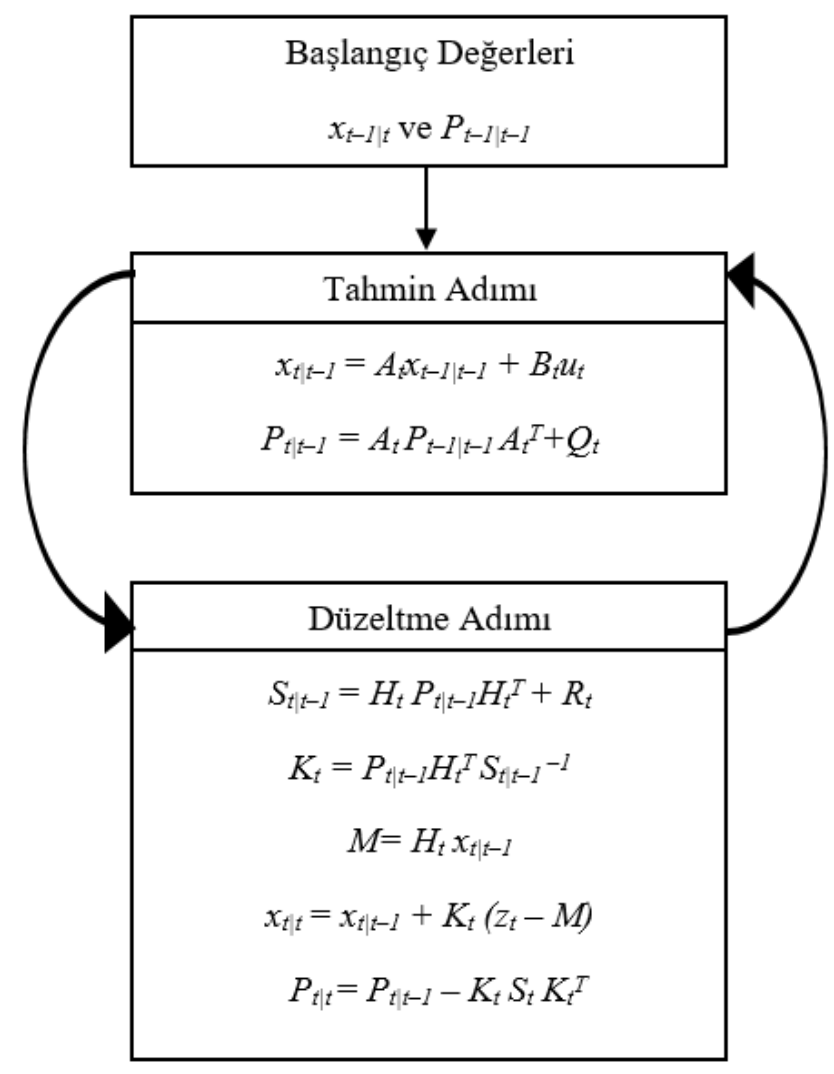

Şekil 5. Ayrık zamanlı Kalman Filtresi akış diyagramı (Flow diagram of the discrete-time kalman filter)

\subsection{Kuaterniyon Tabanlı Genişletilmiş Kalman Filtresi (Quaternion Based Extended Kalman Filter)}

IMU sensörün yönelimi, Şekil 6'da global ve sensör frame olarak adlandirılan koordinat sistemleri ile temsil edilmektedir. Her iki frame orijinde çakışıktır. Sensör frame'de $x_{s}$ sensörün pozitif ileri yönünü, $y_{s}$ sensörün pozitif solunu, $z_{s}$ ise pozitif yukarıy temsil etmektedir. Global frame'de ise $X_{g}$ kuzeyi, $Y_{g}$ batıyı, $Z_{g}$ ise yukarıyı temsil etmektedir. Global frame'deki bir $v$ vektörü $\alpha$ açısı kadar kendi etrafında döndürüldüğünde global frame'e göre Euler değişim açıları elde edilir. Bu açılar $X, Y$ ve $Z$ eksenlerindeki değişimi $\varphi, \theta$, $\psi$ sembolleri ile simgelenen roll, pitch ve yaw açılarıdır. $\mathfrak{R}^{3}$ uzayında bulunan, global frame'e göre sensör yönelimini tanımlayan $\mathfrak{R}^{4}$ uzayındaki vektöre kuaterniyon vektörü denilmektedir [38]. $\mathfrak{R}^{3}$ uzayında Euler açısına bağlı döndürme vektörü tekillik (singularity) problemine sahip olduğundan [39], bu çalışmada hesapsal etkinliği artırmak ve tekillikten kaçınmak için Euler açıları yerine $\mathfrak{R}^{4}$ uzayındaki kuaterniyon vektörü kullanılmıştır. Eş. 3'de $\alpha$ açıları cinsinden bir kuaterniyon vektörü olan $q$ vektörü gösterilmektedir.

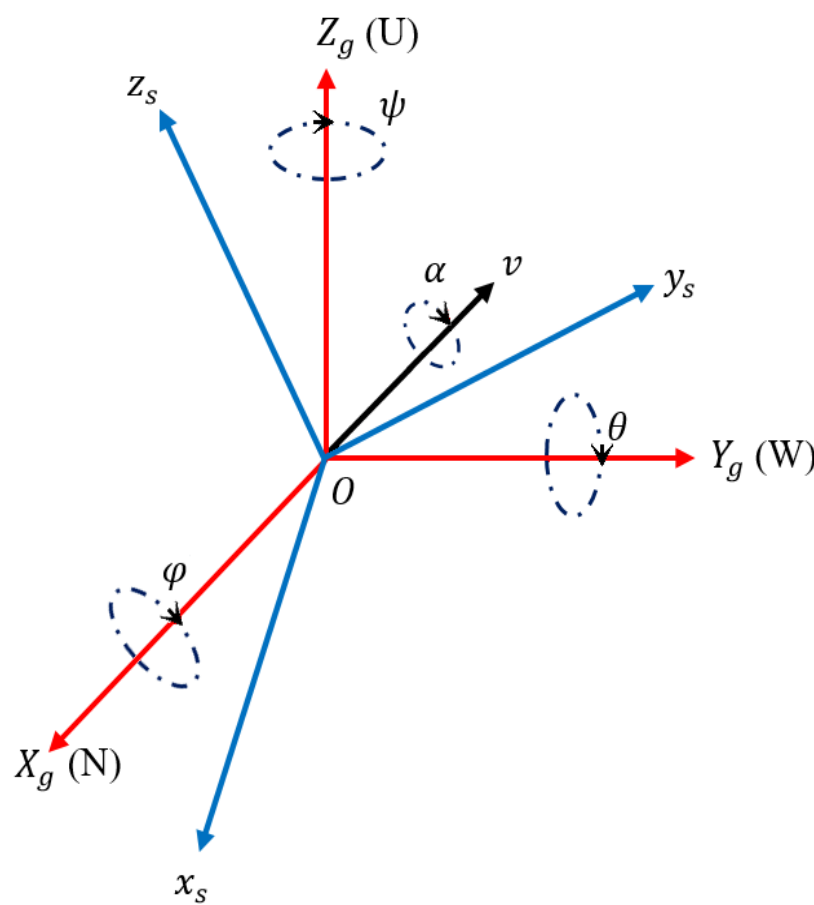

Şekil 6. Global ve sensör frame (Global and sensor frame)

Eş. 4'de konjuge kuaterniyon vektörü, Eş. 5'de ise üç boyutlu bir $v$ vektörün kuaterniyon vektörü ile nasıl dönderildiği verilmiştir [38].

$$
\begin{aligned}
& q=\left[\begin{array}{llll}
q_{0} & q_{1} & q_{2} & q_{3}
\end{array}\right]=\left[\cos \frac{\alpha}{2} r_{x} \sin \frac{\alpha}{2} r_{y} \sin \frac{\alpha}{2} r_{z} \sin \frac{\alpha}{2}\right] \\
& q^{*}=\left[\begin{array}{llll}
q_{0} & -q_{1} & -q_{2} & -q_{3}
\end{array}\right] \\
& v^{g}=q \otimes v^{s} \otimes q^{*}
\end{aligned}
$$

İlk olarak ivmeölçerden gelen $a_{x}$ ve $a_{y}$ değerleri ile Eş. 6' da $\varphi$ (roll) ve Eş. 7'de $\theta$ (pitch) açıları hesaplanmıştır.

$$
\begin{aligned}
& \varphi=\tan ^{-1}\left(\frac{a_{y}}{\sqrt{a_{x}^{2}+a_{z}^{2}}}\right) \\
& \theta=-\tan ^{-1}\left(\frac{a_{x}}{\sqrt{a_{y}^{2}+a_{z}^{2}}}\right)
\end{aligned}
$$

$\mathrm{Bu}$ çalışmada, tasarlanan Genişletilmiş Kalman Filtresinde kullanılan durum vektörü $x$, kuaterniyon ve jiroskop bias verilerinden oluşmaktadır. Sürekli zamanlı doğrusal olmayan sistem denklemi Eş. 8 ve Eş. 9'da verilmiştir [40]. ${ }^{s} \omega_{t}$ jiroskop, ${ }^{s} a_{t}$ ivmeölçer, ${ }^{s} m_{t}$ ise manyetik kuvvetölçerden $t$ anında okunan sensör verilerini temsil etmektedir. Eş. 8'de 
durum vektörü $x_{t}$, Eş. 9'da ivmeölçer ve manyetik kuvvetölçer verilerinden oluşan ölçüm vektörü $z_{t}$ verilmektedir.

$x_{t}=f\left(x_{t-1},{ }^{s} \omega_{t}\right)+w_{t}$

$x_{t-1}=\left[\begin{array}{lllll}q_{0} & q_{1} & q_{2} & q_{3} & b_{w x} \\ b_{w y} & b_{w z}\end{array}\right]^{T}$

$z_{t}=h\left(x_{t}\right)+v_{t}$

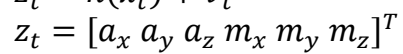

Doğrusal olmayan $f\left(x_{t-1}, \omega\right)$ ve $h\left(x_{t}\right)$ fonksiyonları Eş.10 ve Eş. 11'de verilmiştir [40]. Doğrusal olmayan bu fonksiyonların Jacobian karşılıkları kullanılarak Genişletilmiş Kalman filtresi elde edilmiştir. Denklemdeki $g$ değeri, yerçekimini temsil etmektedir $\left(g=9,81 \mathrm{~m} / \mathrm{s}^{2}\right)$. Başlangıç kuaterniyon değeri Eş. 12'de verilmiştir. Eş. 13'de ise hesaplanan anlık kuaterniyon değerinin sensör verilerinin okunma sıklığını gösteren $\Delta t$ periyot değeri ile çarpılarak integralinin alınması ve nihai yönelim kuaterniyon formülü verilmiştir.

$$
\begin{aligned}
& f\left(x_{t-1},{ }^{s} \widehat{\omega}_{t}\right)={ }_{G}^{S} q_{t}= \\
& \frac{1}{2}\left(\left[\begin{array}{rrr}
-q_{1} & -q_{2} & -q_{3} \\
q_{0} & -q_{3} & q_{2} \\
q_{3} & q_{0} & -q_{1} \\
-q_{2} & q_{1} & q_{0}
\end{array}\right] \quad\left[\begin{array}{l}
\omega_{x}-b_{w x} \\
\omega_{y}-b_{w y} \\
\omega_{z}-b_{w z}
\end{array}\right]\right) \\
& h\left(x_{t}\right)=\left[\begin{array}{c}
2 g\left(q_{1} q_{3}-q_{0} q_{2}\right) \\
2 g\left(q_{2} q_{3}-q_{0} q_{1}\right) \\
g\left(q_{0}^{2}-q_{1}^{2}-q_{2}^{2}+q_{3}^{2}\right) \\
\arctan \left(\frac{2\left(q_{1} q_{2}+q_{0} q_{3}\right)}{q_{0}^{2}-q_{1}^{2}-q_{2}^{2}+q_{3}^{2}}\right)
\end{array}\right] \\
& q_{t=0}=\left[\begin{array}{llll}
1 & 0 & 0 & 0
\end{array}\right] \\
& { }_{G}^{S} q_{t+1}=q_{k}+{ }_{G}^{S} q_{t} * \Delta t
\end{aligned}
$$

Genişletilmiş Kalman Filtresi ile açılar düzeltildikten sonra manyetik kuvvetölçerden gelen verilerle son olarak $\psi$ yaw açıs1 düzeltilerek bütün kuaterniyon değerleri hesaplanmıştır. Elde edilen kuaterniyon değerleri kullanılarak ivme değerlerindeki integral alma işlemi sonucu oluşan hatalar düzeltilmiştir. Şekil 7'de algoritma akış şeması verilmiştir. Doğruluğu artırılan ivme değeri kullanılarak hız ve pozisyon hesaplanarak robotun boru içerisindeki konumu tahmin edilmeye çalışılmıştır.

\section{SONUÇLAR VE TARTIŞMALAR (RESULTS AND DISCUSSIONS)}

Bu bölümde yapılan deneysel çalışmalar hakkında bilgi verilecektir. $\mathrm{Bu}$ çalışmalar aşağıda listelenmektedir: Jiroskop sapma hatasının Genişletilmiş Kalman filtresi ile düzeltilmesi uygulaması. Sizıntı konum tespit uygulamaları - (13, 45 ve 50 metrelik gezinti senaryoları) Uygulama çalışmalarının tamamında IMU sensör verilerinin okunma işlemi Şekil 8a'da gösterilen Banana Pi-M2 bilgisayarı 1398 kullanılarak gerçekleştirilmiştir. Bu bilgisayar yardımıyla alınan veriler Intel I7 işlemci ve $8 \mathrm{~GB}$ ram belleğe sahip bilgisayarda Matlab 2014b ortamında off-line olarak işlenmiştir. Şekil 8b'de ise kullanılan $100 \mathrm{~Hz}$ frekansında sensörden okunan anlık ivmeölçer, jiroskop ve manyetik kuvvetölçer verileri gösterilmektedir.

\subsection{Jiroskop Sapma Hatasının Genişletilmiş Kalman Filtresi ile Düzeltilmesi Uygulamasl \\ (Correction of Gyroscope Deviation Error with Extended Kalman Filter)}

$\mathrm{Bu}$ çalışmada konum tahmini iki aşamalı olarak gerçekleştirilmiştir. Birinci aşamada sensörlerden okunan veriler kullanılarak yönelim açıları ve kuaterniyon vektörleri hesaplanmıştır. İkinci aşamada ivmeölçere ait değerler düzeltilerek integral alma işlemi sonucu oluşan hatalar en aza indirgenmeye çalışılmıştır. Elde edilen düzeltilmiş ivmeölçer verileri ile konum hesaplanmıştır. Şekil 9'da Genişletilmiş Kalman filtresi uygulanması sonucu elde edilen roll ve pitch açı değerleri verilmiştir. İlk olarak X ekseninde $-90^{\circ}$ döndürme işlemi yapılmış ve tekrar başlangıç konumuna geçilerek sensör aynı eksende $+90^{\circ}$ döndürülmüştür. Aynı işlemler Y ekseni için de gerçekleştirilmiştir. Şekillerde kırmızı renk ile gösterilen açılar ivmeölçer verileri kullanılarak Eş. 6 ve Eş. 7 ile hesaplanan roll ve pitch açılarıdır (Şekil 9a ve 9b). Yeşil renk jiroskoptan okunan açısal değerlerin integrale tabi tutulmuş kümülatif şeklidir. Buradan jiroskobun giderek artan sapma hatası açıkça görülmektedir. Ayrıca pitch açısının verildiği şekilde 13-17. saniyeler arasında ivmeölçerden gelen verideki hatanın da Genişletilmiş Kalman filtresi tarafından düzeltildiği ve sensör füzyonun gerçekleştiği gözlemlenmiştir.

\subsection{Sizıntı Konum Tespit Deneyleri \\ (Leakage Position Detection Experiments)}

Bu bölümde, önerilen sızıntı tespit sistemi (mini bilgisayar, SD kart, IMU, mikrofon, kayıt ve tespit yazılımları) ile gerçek ortamda yapılan test çalışmaları ve elde edilen sonuçlar verilecektir. Test aşaması iki bağımsız işlemi içermektedir: 1) Kayıt (veri toplama); 2) Tespit (veri işleme). Normalde kayıt işlemi, yer altında, boru içerisinde ve suyun itme kuvvetiyle hareket eden düzenek içerisinde elde edilmelidir. Ancak bu çalışmada veri kayıt işlemi yer altında değil yer üstünde yapılan bir gezintiden elde edilmiştir. Çünkü ön aşama olarak gerçekleştirilen bu çalışmada birinci öncelik, Genişletilmiş Kalman Filtresi tabanlı gezinti konumu tahmin algoritmasının doğru olarak çalışmasıdır. Bu nedenle üç farklı gezinti senaryosu belirlenmiş ve kayıt cihazı belirlenen bu konumlarda manuel olarak hareket ettirilmiştir. Gezinti güzergâhı üzerinde belirli noktalarda su akışı sağlanarak çatlak sesinin elde edebilmesi sağlanmıştır. Böylece ortam sesini sürekli kaydeden kayıt cihazı bu noktaların yanından geçerken su akış sesini de kaydetmiş olacaktır. Kapalı bir ortamda gerçekleştirilen deneylerde üç farklı gezinti senaryosu gerçekleştirilmiştir. Gömülü bilgisayar yardımıyla geliştirilen sistemde Genişletilmiş Kalman Filtresi kullanılarak her bir senaryodaki sanal sızıntı konumları tahmin edilmeye çalışılmıştır. 


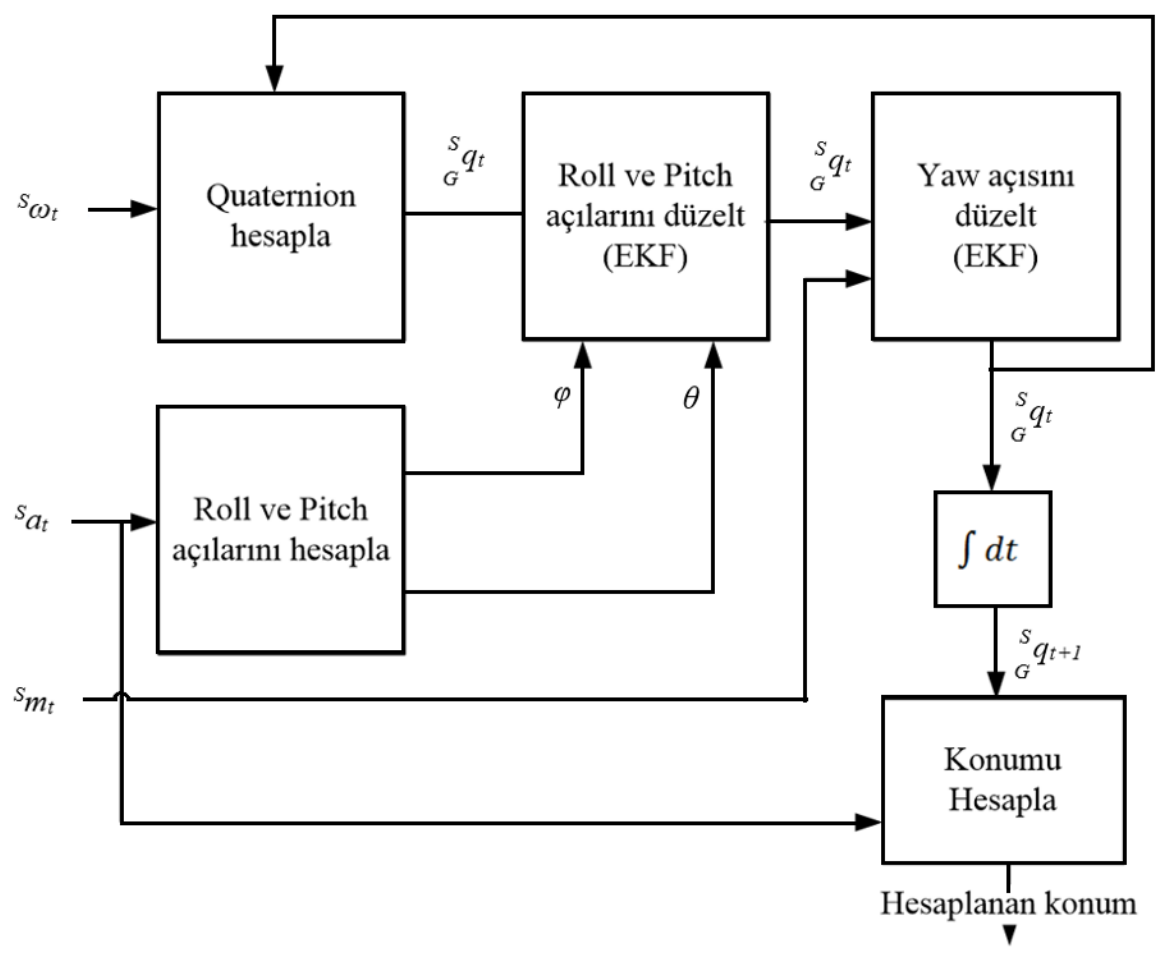

Şekil 7. Önerilen Kuaterniyon tabanlı genişletilmiş kalman filtresi akış diyagramı (Proposed quaternion-based extended kalman filter flow diagram)

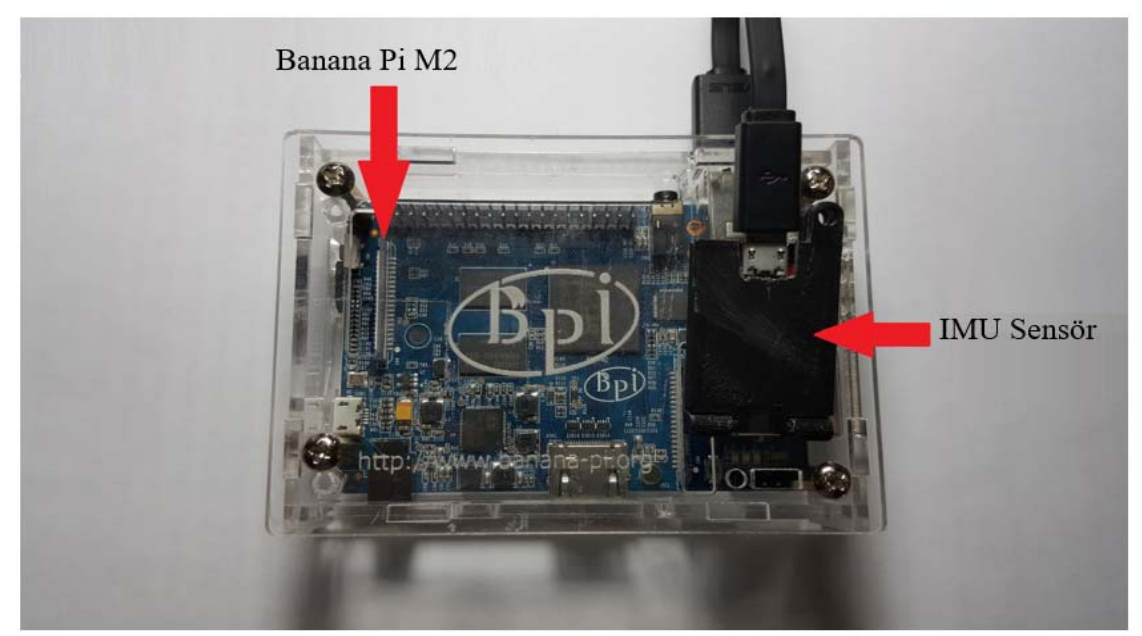

(a)

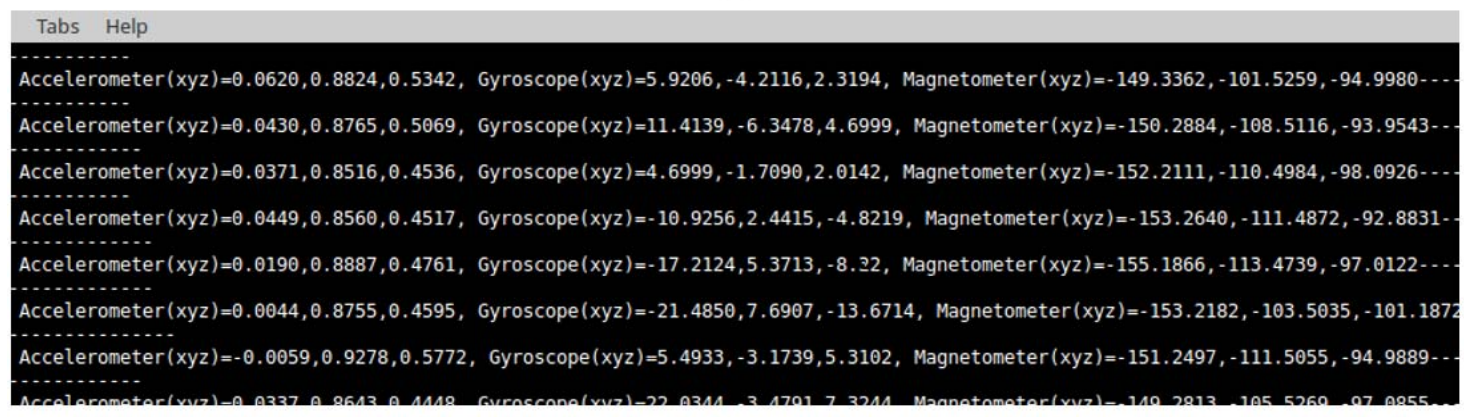

(b)

Şekil 8. a) Banana Pi M2 kartı ve IMU sensör b) IMU verilerini toplayan gömülü yazılımın ekran görüntüsü (a)Banana Pi M2 board and IMU sensor b) Screenshot of embedded software that collects IMU data) 


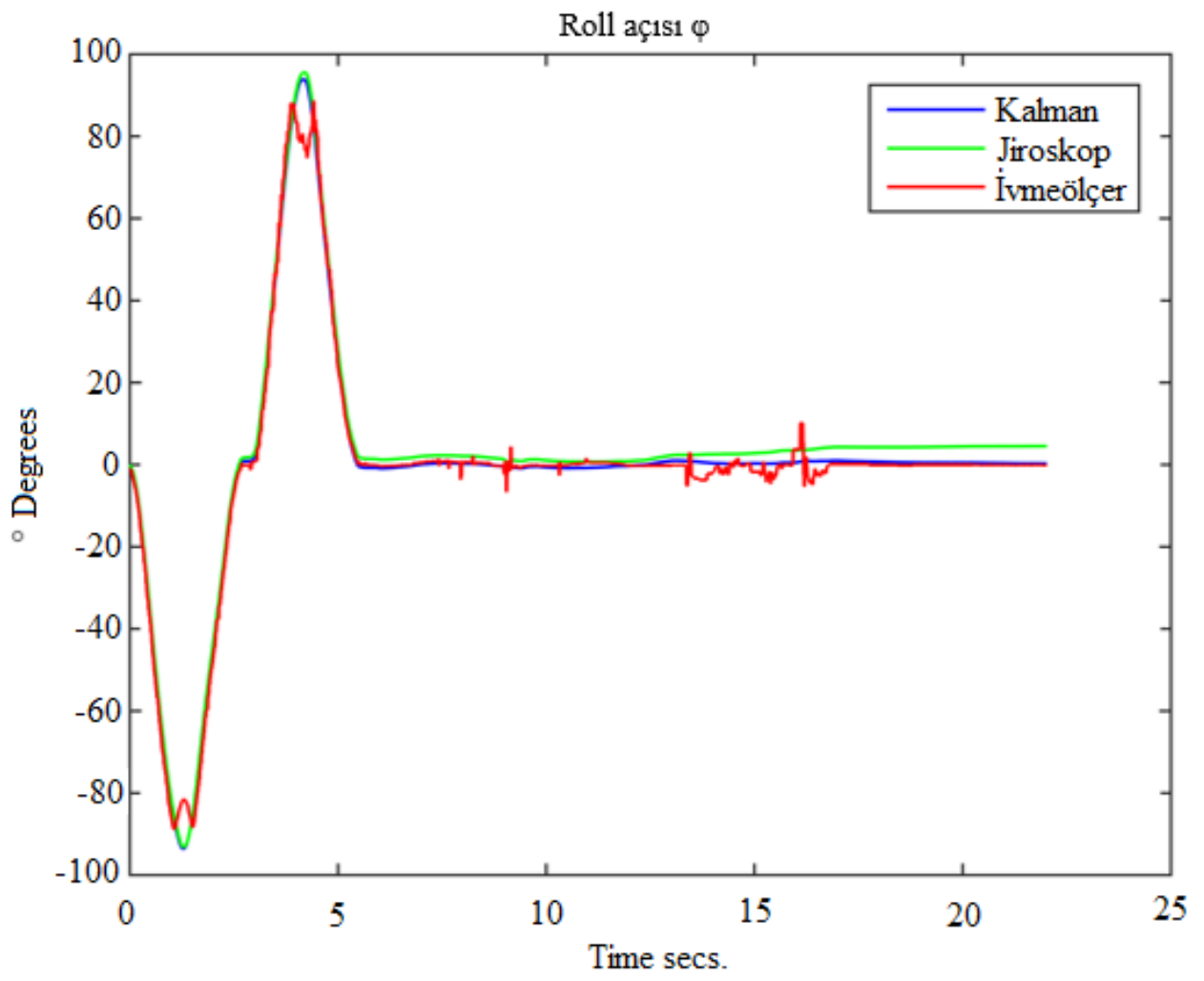

(a)

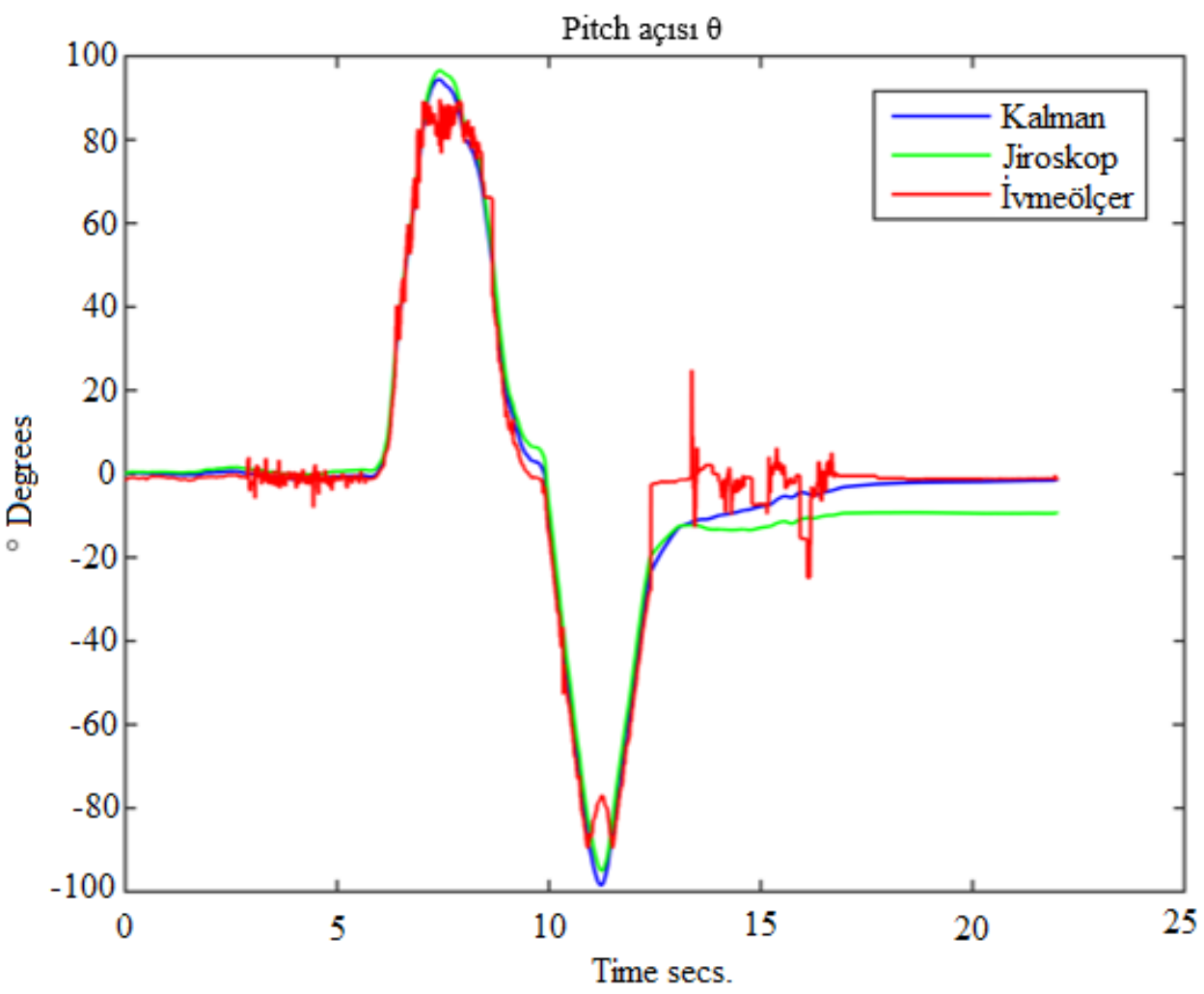

(b)

Şekil 9. Jiroskop sapma hatasının genişletilmiş kalman filtresi ile düzeltilmesi a) roll açısı b) pitch açısı (Correcting gyroscope drift error by extended kalman filter a) roll angle b) pitch angle) 


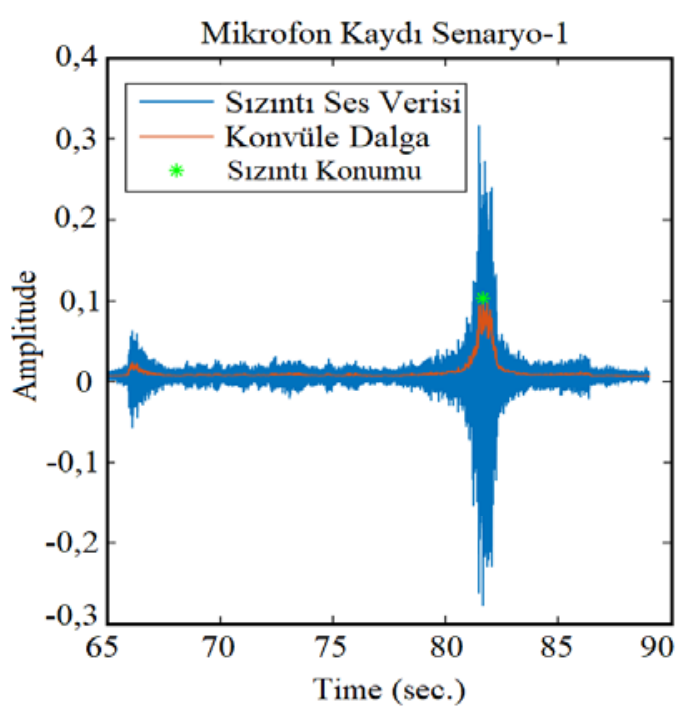

(a)

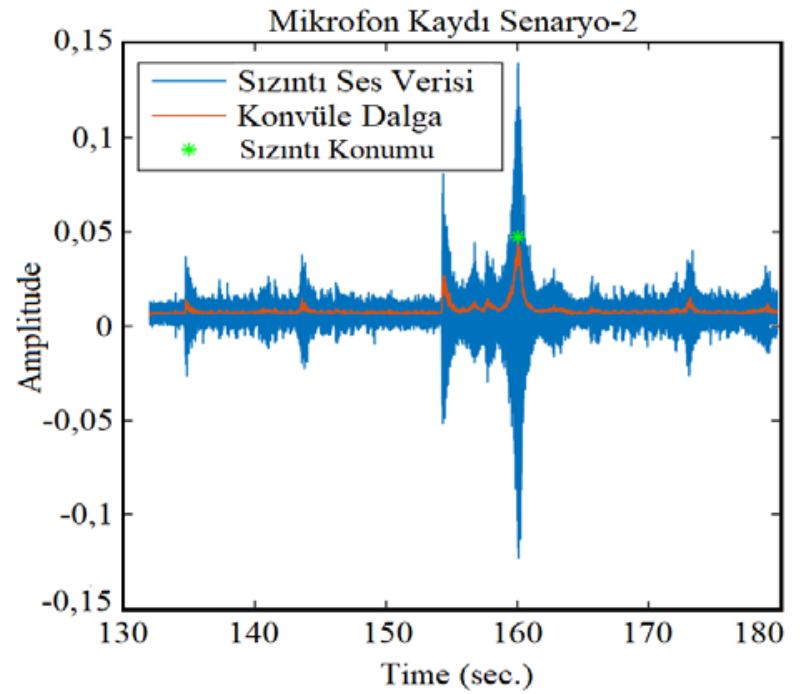

(b)

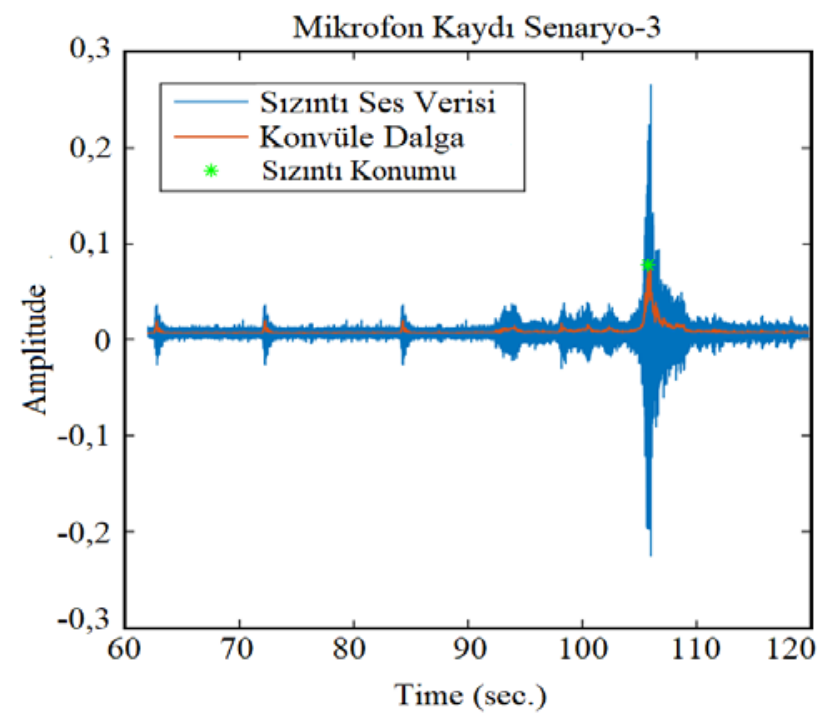

(c)

Şekil 10. Ses verisi kullanılarak sızıntı konumunun tespit edilmesi a) Senaryo-1 b) Senaryo-2 c) Senaryo-3 (Detection of leakage location using sound data a) Scenario-1 b) Scenario-2 c) Scenario-3)

Tablo 1. Sızıntı senaryolarına ait gerçek ve tahmin edilen konum değerleri (Real and estimated leakage position values)

\begin{tabular}{lllll}
\hline Senaryo & $\begin{array}{l}\text { Gidilen Toplam } \\
\text { Mesafe }(\mathrm{m} .)\end{array}$ & $\begin{array}{l}\text { Sizınt1 } \\
\text { Konumu (m.) }\end{array}$ & $\begin{array}{l}\text { Hesaplanan } \\
\text { Konum }(\mathrm{m} .)\end{array}$ & $\begin{array}{l}\text { Hata } \\
(\mathrm{m} .)\end{array}$ \\
\hline Senaryo 1 & 23,45 & 13,4 & 13,307 & 0,093 \\
Senaryo 2 & 45,77 & 25,23 & 25,161 & 0,069 \\
Senaryo 3 & 50 & 35,165 & 35,270 & $-0,105$ \\
\hline
\end{tabular}

Birinci senaryoda gezinti güzergâhının toplam uzunluğu 23,45 metre olarak belirlenmiş ve sağa sola sapma olmadan yaklaşık olarak $45^{\circ}$ 'lik bir açıyla kuzey-doğu yönünde kayıt sisteminin hareketi sağlanmıştır. Çatlak konumu başlangıç noktasindan 13,4 metre uzaklıktadır. İkinci senaryoda toplamda 45,77 metrelik kapalı bir sistem tasarlanmıştır. Çatlak konumu hareket başlangıç noktasından 25,23 metre uzaklıktadır. Üçüncü senaryoda ise toplamda 50 metre gidilmiş ve çatlak konumu 35,165 metre uzaklıktadır. Tüm senaryolarda ilk olarak ses verisi işlenmiş ve sızıntının saniye cinsinden konumu tespit edilmiştir. Şekil 10'da mavi renkli sinyal boru içerisinde mikrofondan alınan su sesini, kırmızı renkli sinyal konvüle edilmiş sesi, yeşil nokta ise sızıntının oluştuğu noktayı saniye cinsinden temsil etmektedir. Şekil 11'de gerçek konum mavi üçgenle tahmin edilen sızıntı konumu ise kırmızı kare ile verilmiştir. Boru içerisindeki IMU sensör hareketinin kuzey-doğu yönünde olduğu açıkça görülmektedir. Bu durum sensör frame'den 
global frame'e geçişin doğru olarak gerçekleștiğini ve yönelimin doğru hesaplandığııı ispatlamaktadır. Tablol'de oluşturulan senaryolara ait gerçek ve hesaplanan konum bilgileri verilmektedir. Genişletilmiş Kalman Filtresi ile tasarlanan sistemin hatasının oldukça düşük olduğu görülmektedir. Şekil 12 ve Şekil 13'de ikinci ve üçüncü senaryoya ait gerçek ve tahmin edilen sızıntı konumları verilmiştir.

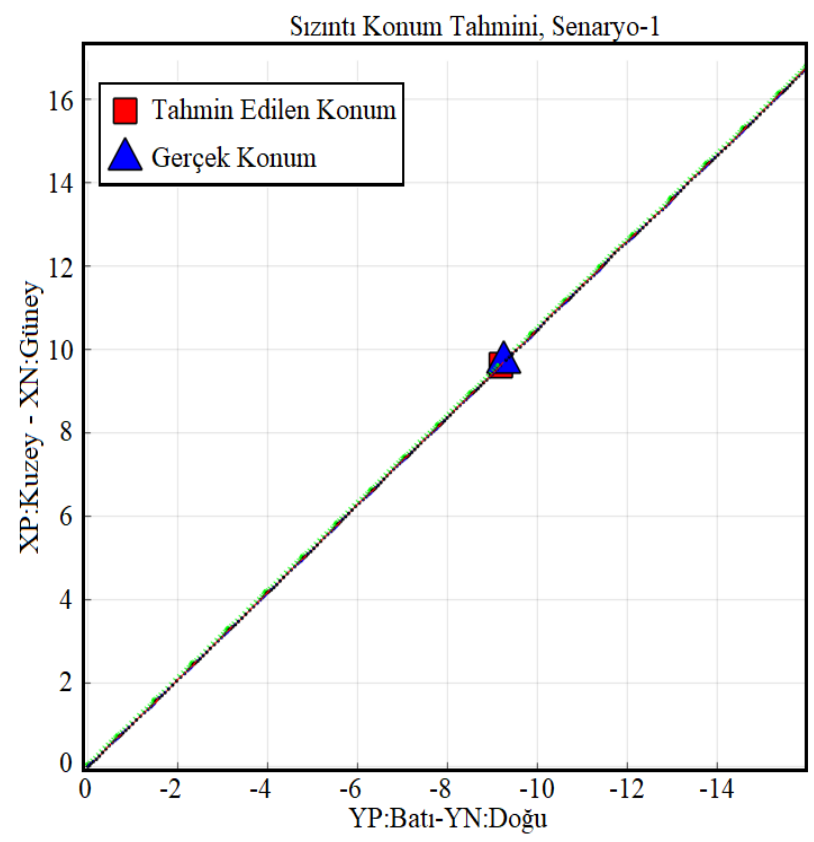

Şekil 11. Gerçek ve tahmin edilen sızıntı konumu Senaryo1 (Real and estimated leakage position Scenario-1)

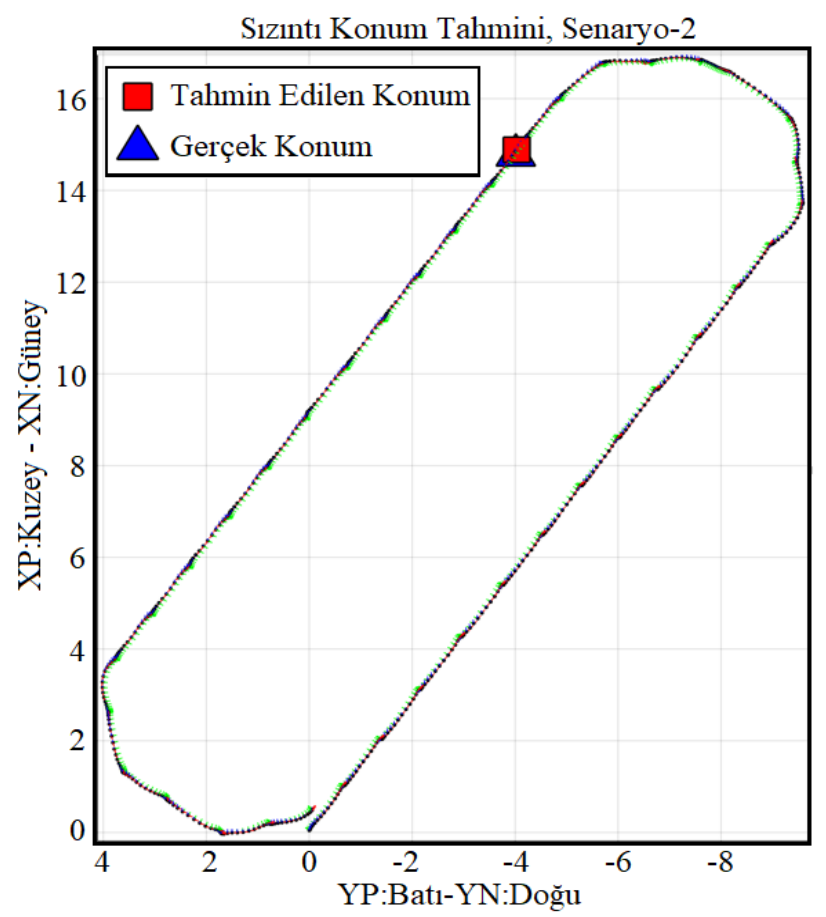

Şekil 12. Gerçek ve tahmin edilen sızıntı konumu Senaryo2 (Real and estimated leakage position Scenario-2) 1402

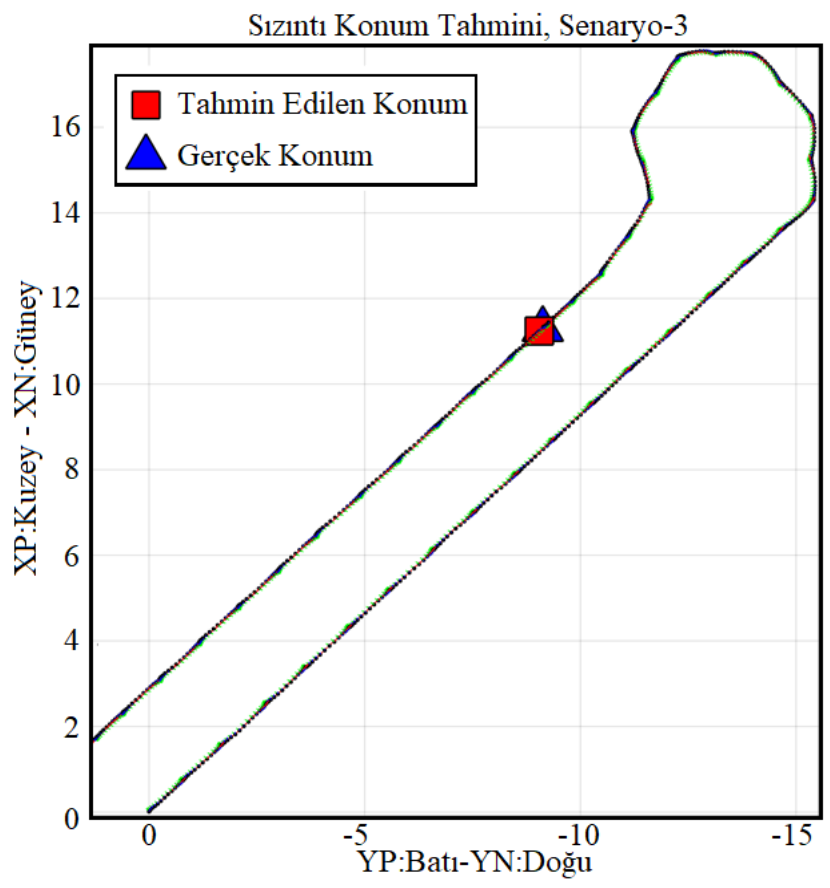

Şekil 13. Gerçek ve tahmin edilen sızıntı konumu Senaryo3 (Real and estimated leakage position Scenario-3)

\section{SONUCLAR (CONCLUSIONS)}

$\mathrm{Bu}$ çalışmada şebekelerde su kaybına sebep olan sızıntı konumunu boru içinde hareket ederek tespit edebilecek robotun ön çalışması yapılmıștır. Oluşturulan farklı sızıntı tespit senaryolarında, gerçekleştirme aşamasına geçildiğinde ARM işlemcili bir bilgisayar kullanılarak IMU sensör verisi ile eş zamanlı olarak ses kaydı yapılmıştır. Elde edilen sensör verileri ve ses kaydı ikinci bir bilgisayara aktarılarak sızıntı konum tespiti işlemine geçilmiştir. Genişletilmiş Kalman Filtresi temeline dayanan sensör füzyonu metodu ile sensör verileri kullanılarak konum tespiti yapılmış ve kabul edilebilir hata oranına sahip sonuçlar elde edilmiştir. GPS sinyallerinden bağımsız olarak sadece IMU sensör ile çalışan sistemde sensör maliyeti azaltılmıștır. Gelecek çalışmada su altına inilerek hidrofon yardımıyla alınan ortam sesinin incelenmesi ve fiziksel olarak tamamlanacak robotla sızıntı konumun tespiti planlanmıştır.

\section{SIMGELER (SYMBOLS)}

$A_{t} \quad$ : Durum geçiş matrisi

$B_{t} \quad:$ Kontrol giriş matrisi

$b_{w} \quad:$ : Jiroskop bias değeri

$H_{t} \quad$ : Durum vektörünü ölçüm domainine taşıyan dönüşüm matrisi

$K_{t} \quad$ : Kalman kazancı

$P_{t \mid t} \quad:$ Soncul hata kovaryans matrisi

$P_{t \mid t-1} \quad:$ Öncül hata kovaryans matrisi

$P_{t-1 \mid t-1} \quad:$ Bir önceki adıma ait soncul hata kovaryansı

$q \quad:$ : Kuaterniyon matrisi

$q^{*} \quad:$ Konjuge kuaterniyon matrisi

$q_{t=0} \quad$ : Başlangıç kuaterniyon matrisi

$q_{t+1} \quad$ : Hesaplanan kümülatif kuaterniyon değeri 
$q_{t} \quad:$ Hesaplanan anlık kuaterniyon değeri

$Q_{t} \quad$ : Gürültü kovaryans matrisi

$R_{t} \quad$ : Düzeltme adımı gürültü kovaryansı

$S_{t \mid t-1}: z_{t}$ ölçüm değerinin tahmini öncül kovaryansı

$s_{a_{t}} \quad$ : Üç boyutlu ivmeölçer vektörü

$s_{m_{t}} \quad:$ Üç boyutlu manyetik kuvvetölçer vektörü

${ }^{S} \omega_{t} \quad$ : Üç boyutlu jiroskop vektörü

$u_{t} \quad: t$ anındaki kontrol vektörü

$v \quad:$ Üç boyutlu bir vektör

$v^{s} \quad:$ Üç boyutlu sensör vektörü

$v^{g} \quad:$ Üç boyutlu global vektör

$v_{t} \quad: t$ anındaki ölçüm hatası

$w_{t} \quad: t$ anındaki durum hatası

$X_{g} \quad$ : Global frame'de kuzey yönü

$x_{s} \quad$ : Sensör frame'de sensörün pozitif ileri yönü

$x_{t} \quad: t$ anındaki durum vektörü

$x_{t \mid t-1} \quad$ : Öncül durum tahmini

$x_{t-1 \mid t-1} \quad$ : Bir önceki adıma ait soncul durum tahmini

$Y_{g} \quad$ : Global frame'de bat1 yönü

$y_{s} \quad:$ Sensör frame'de sensörün pozitif sol yönü

$Z_{g} \quad$ : Global frame'de yukarı yön

$z_{s} \quad$ : Sensör frame'de sensörün pozitif yukarı yönü

$z_{t} \quad$ : Sensörlerden okunan ölçüm vektörü

$\varphi \quad$ : Derece türünden roll açı değeri

$\theta \quad$ : Derece türünden pitch açı değeri

$\psi \quad$ : Derece türünden yaw açı değeri

$\Delta t \quad$ : IMU sensöre ait örnekleme periyodu

\section{TEŞEKKÜR (ACKNOWLEDGEMENT)}

$\mathrm{Bu}$ çalışma Türkiye Bilimsel ve Teknolojik Araştırma Kurumu 3501-Kariyer Projeleri programı tarafindan desteklenmiştir (Proje Numarası: 215E075).

\section{KAYNAKLAR (REFERENCES)}

1. Dede Ö.T., Sezer M., The Application of Canadian Water Quality Index (CWQI) Model for The Assessment of Water Quality of Aksu Creek, Journal of the Faculty of Engineering and Architecture of Gazi University, 32 (3), 909-917, 2017.

2. Ulaş A., Ovalı P.K., A New Approach to Concentric Circles Theory As Urban Growth Model in Concept of Physical Theories: Force Model within Kinetic and Potential Urbanization, Journal of the Faculty of Engineering and Architecture of Gazi University, 32 (2), 393-401, 2017.

3. Mcneill L.S., Edwards M., Iron Pipe Corrosion in Distribution Systems, J. Am. Water Works Assn., 93 (7), 88-100, 2001

4. Alegre H., Baptista J.M., Jr E.C., Performance Indicators for Water Supply Services: Third Edition, IWA Publishing, London, United Kingdom, 2016.

5. Marin P., Kingdom B., Liemberger R., The Challenge of Reducing Non-Revenue Water (Nrw) in Developing Countries - How The Private Sector Can Help : A Look at Performance-Based Service Contracting, The World Bank, 39405, December 2006.
6. Hooda S.M., Rajasthan Water Assessment : Potential for Private Sector Interventions, International Finance Corporation, World Bank, New Delhi, 2017.

7. Puust R., Kapelan Z., Savic D.A., Koppel T., A Review of Methods For Leakage Management in Pipe Networks, Urban Water J., 7 (1), 25-45, 2010.

8. Hunaidi O., Wang A., Bracken M., Gambino T., Fricke C., Acoustic Methods for Locating Leaks in Municipal Water Pipe Networks, International Conference on Water Demand Management, Dead Sea-Jordan, 1-14, May 30- June 3, 2004.

9. Sewerin AQUAPHON 200 Leak-Survey-Tool. http://muinin.com/aquaphon-a-200/. Erişim tarihi: Ocak 4, 2017.

10. Lay-Ekuakille A., Griffo G., Vergallo P., Robust Algorithm Based on Decimated Padè Approximant Technique for Processing Sensor Data in Leak Detection in Waterworks, IET Sci. Meas. Technol., 7 (5), 256-264, 2013.

11. Ben-Mansour R., Habib M.A., Khalifa A., YoucefToumi K., Chatzigeorgiou D., Computational Fluid Dynamic Simulation of Small Leaks in Water Pipelines for Direct Leak Pressure Transduction, Comput. Fluids, 57, 110-123, 2012.

12. Begovich O., Pizano-Moreno A., Garcia-Malacara E., Besançon G., How Can The Temperature Affect the Performance of a Classical Pipeline Model When Plastic Pipes Are Used?, 8th International Conference on Electrical Engineering, Computing Science and Automatic Control, Merida City-Mexico, 1-6, October 26-28, 2011.

13. Goh J.H., Water Pipe Leak Detection Using Electromagnetic Wave Sensor for the Water Industry, 2011 IEEE Symposium on Computers Informatics, Kuala Lumpur-Malaysia, 290-295, March 20-23, 2011.

14. Lay-Ekuakille A., Vendramin G., Trotta A., Robust Spectral Leak Detection of Complex pipelines Using Filter Diagonalization Method, IEEE Sens. J., 9 (11), 1605-1614, 2009.

15. Daneti M., On Using Double Power Spectral Density Information for Leak Detection, 2013 IEEE International Conference on Industrial Technology, Cape Town-Western Cape-South Africa, 1162-1167, February 25-28, 2013.

16. Kadri A., Abu-Dayya A., Stefanelli R., Trinchero D., Characterization of an Acoustic Wireless Sensor for Water Leakage Detection in Underground Pipes, 2013 1st International Conference on Communications, Signal Processing and Their Applications, SharjahUnited Arab Emirates, 1-5, February 12-14,2013.

17. Ridao P., Carreras M., Ribas D., Garcia R., Visual Inspection of Hydroelectric Dams Using an Autonomous Underwater Vehicle, J. Field Rob., 27 (6), 759-778, 2010.

18. Cataldo A., Cannazza G., Benedetto E. D., Giaquinto N., A New Method for Detecting Leaks in Underground Water Pipelines, IEEE Sens. J., 12 (6), 1660-1667, 2012.

19. Zhang L., Wu Y., Guo L., Cai P., Design and Implementation of Leak Acoustic Signal Correlator for 
Water Pipelines, Information Technology Journal, 12 (11), 2195-2200, 2013.

20. Rajeev P., Kodikara J., Chiu W.K., Kuen T., Distributed Optical Fibre Sensors and Their Applications in Pipeline Monitoring, Key Engineering Materials, 558, 424-434, 2013.

21. Ayala-Cabrera D., Herrera M., Izquierdo J., OcañaLevario S.J., Pérez-García R., GPR-Based Water Leak Models in Water Distribution Systems, Sensors, 13 (12), 15912-15936, 2013.

22. NDE Pipeline Inspection. https://www.ndeed.org/AboutNDT/SelectedApplications/PipelineInspec tion/ PipelineInspection.htm. Erişim tarihi: Ocak 21, 2017.

23. Barbian O.A., Handbook Automated Ultrasonic Testing Systems-IIW Handbook, DVS-Verlag, Düsseldorf, Germany, 2008.

24. Inuktun - World-class Remotely Controlled Camera Robotic Pipe Inspection Systems and Robotic Crawlers. http://www.inuktun.com/crawler-vehicles/. Erişim tarihi: Ocak 21, 2017.

25. PipelineExplorerOverview.http://www.nrec.ri.cmu.edu/ projects/explorer/Erişim tarihi: Ocak 21, 2017.

26. Ahrary A., Tian L., Kamata S., Ishikawa M., An Autonomous Sewer Robots Navigation Based on Stereo Camera Information, 17th IEEE International Conference on Tools with Artificial Intelligence, Hong Kong-China, 634-639, November 14-16, 2005.

27. Mazumdar A., Asada H.H., Pulse Width Modulation of Water Jet Propulsion Systems Using High-Speed Coanda-Effect Valves, J. Dyn. Syst. Meas. Contr., 135 (5), 051019-051019-11, 2013.

28. Mechanical-Emerging Construction Technologies. http://wpvcemweb02.itap.purdue.edu/ect/links/ technologies/mechanical/SmartBall_LeakDetection.asp x. Erişim tarihi: Ocak 23, 2017.

29. Parsa K., Lasky T.A., Ravani B., Design and Implementation of a Mechatronic, All-Accelerometer Inertial Measurement Unit, IEEE/ASME Trans. Mechatron., 12 (6), 640-650, 2007.

30. Hao Y., Yuan W., Xie J., Shen Q., Chang H., Design and Verification of a Structure for Isolating Packaging
Stress in SOI MEMS Devices, IEEE Sensors Journal, 17 (5), 1246-1254, 2017.

31. Elmenreich W., Sensor Fusion in Time-Triggered Systems, Dissertation, Vienna University of Technology, Austria, 2002.

32. Li C., Yang C., Wan J., Annamalai A. S., Cangelosi A., Teleoperation Control of Baxter Robot Using Kalman filter-based Sensor Fusion, Syst. Sci. Control Eng., 5 (1), 156-167, 2017.

33. Zhang T., Liao Y., Attitude measure system based on extended Kalman filter for multi-rotors, Comput. Electron. Agric., 134, 19-26, 2017.

34. Liu Y., Gong S., Lu Y., Estimation of Inertial/Magnetic Sensor Orientation for Human-Motion-Capture System, 2017 2nd International Conference on Control and Robotics Engineering (ICCRE), Bangkok-Thailand, 175-179, April 1-3, 2017.

35. Qiu S., Wang Z., Zhao H., Qin K., Li Z., Hu H., Inertial/Magnetic Sensors Based Pedestrian Dead Reckoning by means of Multi-Sensor Fusion, Inf. Fusion, 39, 108-119, 2018.

36. Bishop G., Welch G., An Introduction to the Kalman Filter, University of North Carolina SIGGRAPH 2001 course notes, ACM Inc., North Carolina-U.S.A., 2001.

37. Faragher R., Understanding the Basis of the Kalman Filter Via a Simple and Intuitive Derivation Lecture Notes., IEEE Signal Process Mag., 29 (5), 128-132, 2012.

38. Kuipers J.B., Quaternions and Rotation Sequences: A Primer with Applications to Orbits, Aerospace and Virtual Reality. Princeton University Press, Princeton, N.J.-U.S.A., 2002.

39. Alaimo A., Comparison between Euler and Quaternion Parametrization in UAV dynamics, AIP Conference Proceedings, 1558 (1), 1228-1231, 2013.

40. Jang J.S., Liccardo D., Automation of Small UAVs Using a Low Cost Mems Sensor and Embedded Computing Platform, 2006 IEEE/AIAA 25th Digital Avionics Systems Conference, Portland-Oregon-USA, 1-9, October 15-18, 2006. 